\title{
A single-tree compatible biomass model of Quercus variabilis Blume forests in North China*
}

\author{
Conghui Zheng • Euan G. Mason • Liming Jia · Songpo Wei $\cdot$ Caowen Sun $•$ Jie Duan
}

Trees: Structure and Function. 01/2015

\begin{abstract}
Key message Fitting and comparing three sets of compatible biomass models for prediction of biomass or carbon stocks of natural and planted Quercus variabilis Blume forests.

Abstract To make the sum of estimated values from biomass models of various components of a tree equal to estimated tree total biomass for Quercus variabilis Blume (cork oak) forests in North China, single-tree compatible biomass models were developed. 100 trees from 100 plots in North China were felled to obtain biomass of aboveground components, and roots of 19 of those trees were extracted for measurement of root biomass. After Box-Cox transformations of variables, two sets of independent component biomass models with a dummy variable in models to define stand origin were separately built using linear mixed effects analyses (one set of models with site as a random factor; the other set without any random factor). Then three methods were compared to force compatibility of the biomass models: sums of linear mixed effects models, sums of linear models, and simultaneous equation fits based on linear models. Model parameters were estimated by ordinary least squares (OLS) or seeming unrelated regression procedures (SUR). Coefficients of determination $\left(r^{2}\right)$, root mean square error (Rmse), residuals plots and histograms of residuals indicated that models fitted with sums of linear mixed effects models were the least biased and most precise at estimating total above-ground biomass. Further testing for the linear mixed effects models with jackknife validation and prediction sum of squares (PRESS) statistics indicated that the compatible biomass models can be used to predict biomass or carbon stocks of cork oak forests in North China within specific tree diameter at breast height and height ranges.
\end{abstract}

Keywords Quercus variabilis Blume · dummy variable $\cdot$ Box-Cox transformation · linear mixed effects models $\cdot$ seeming unrelated regression procedures $\cdot$ jackknife validation

\section{Introduction}

Forests play an important role in the mitigation of global climate change by sequestering $\mathrm{CO}_{2}$. Estimating forest biomass with models facilitates indepth studies of ecosystem energy flows and carbon cycling. Monitoring of forest biomass and carbon stocks and establishment of biomass models suitable for larger areas are therefore increasingly important (Case and Hall, 2008; Gurdak et al., 2014; Jenkins et al., 2003; Muukkonen, 2007; Návar, 2009; Ritchie et al., 2013; Snorrason and Einarsson, 2006; Vallet et al., 2006). Both linear and nonlinear models are commonly used for biomass modelling

\footnotetext{
${ }^{*}$ C. Zheng and E. G. Mason have equally contributed to this work and should be regarded as co-first authors. C. Zheng $\cdot$ L. Jia $\cdot$ S. Wei $\cdot$ C. Sun $\cdot$ J. Duan

Ministry of Education Key Laboratory of Silviculture and Conservation, Beijing Forestry University, Beijing, China

E. G. Mason

School of Forestry, University of Canterbury, Christchurch, New Zealand

L. Jia

Corresponding author e-mail: jlm@bjfu.edu.cn tel.: +861062337055 fax: +861062337055
} 
(Durkaya et al., 2009; Sajdak et al., 2014; Schmidt et al., 2009; Torres Vélez and Del Valle, 2007; Zeng et al., 2011; Zianis et al., 2004). Moreover, compatible biomass modelling systems have been proposed and applied to ensure compatibility between total biomass models and component biomass models. Researchers have developed two principal ways of creating compatible biomass models: (1) the total biomass regression function is defined as the sum of separately calculated best regression functions of component biomasses; (2) joint-generalized least squares regression, like seemingly unrelated regressions (SUR), two-stage least-squares methods (2SLS), three-stage least-squares methods (3SLS) and generalized method of moments (GMM) (António et al., 2007; Balboa-Murias et al., 2006; Bi et al., 2010; Brandeis et al., 2006; Castedo-Dorado et al., 2012; Gómez-García et al., 2013; Gómez-García et al., 2014; Hasenauer et al., 1998; Carvalho and Parresol, 2003; Li and Zhao, 2013; Menéndez-Miguélez et al., 2013; Parresol, 1999, 2001; Ruiz-Peinado et al., 2011; Shaiek et al., 2011).

Oak forest accounts for $15.89 \%$ of forest stand area and $13.30 \%$ of forest stand volume in China (Luo et al., 2009). Quercus variabilis Blume (Cork oak) is used for timber, cork, soil and water conservation, and is mainly distributed in the areas of Taihang Mountain and Yan Mountain in North China. A large number of biomass models of oak have been created in Europe, North America, Portugal, Spain, Greece, and China (Bao et al., 1984; Canadell et al., 1988; Zianis et al., 2005; Ter-Michaelian et al., 1997; Paulo and Tomé, 2010; Fonseca and Parresol, 2001; Tian et al., 1997; Zianis et al., 2011). In most models tree height $(H)$, diameter at breast height $(D B H)$ or their combination $\left(d^{2} h\right)$ are independent variables. Until now, Quercus variabilis Blume compatible biomass models in North China have not been developed. The objective of the study described here was therefore to establish and compare three sets of compatible biomass models applied to natural and planted Quercus variabilis Blume forests in North China: (1) A total biomass regression function defined as the sum of separately calculated best linear mixed effects models of the component biomasses (sums of linear mixed effects models); (2) A total biomass regression function defined as the sum of separately calculated best linear models of the component biomasses (sums of linear models); and (3) simultaneous equations of linear models of biomass based on seemingly unrelated regressions (SUR).

\section{Methods}

\section{Measurements}

100 cork oak plots in 13 stands with different site conditions and age distributions were created in the following locations: Gao-Luo forestry station, Qi-Jiahe forestry station, Bei-Tan forestry station and Heng-He forestry station of Zhong-tiaoshan region in Shanxi province, collective forests of Da-Geliao village in Xingtai city of Hebei province, Si-Zuolou forestry station and Xi-Shan forestry station in Beijing. 67 plots in naturally regenerated forest and 33 plots in plantations were included and the area of each plot was $20 \mathrm{~m} \times 20 \mathrm{~m}(0.04 \mathrm{ha})$. Measured variables were as follows: (1) Single tree variables including diameter at breast height, tree height, crown width, crown length; (2) Biomass data of various components obtained by fully weighing individual tree components in the mentioned plots including aboveground biomass of each component of 100 trees closest to the average within each plot (67 naturally regenerated trees and 33 planted trees) and root biomass of 19 of those 100 trees (12 naturally regenerated trees and 7 planted trees). Additionally, another 13 sets of root biomass data can be found in two related reports (Bao et al., 1984; Tian et al., 1997). For the biomass data, subsamples were also selected and weighed to get fresh mass in the field. Then all the subsamples were oven-dried at $85^{\circ} \mathrm{C}$ in a laboratory until a constant mass was reached. Using the ratio of dry mass to fresh mass, biomass of 
each component was computed including stem woody biomass, stem bark biomass, branch biomass, foliage biomass, total stem biomass (including bark), total crown biomass and total aboveground biomass for all the 100 trees. For 32 trees, root biomass and total tree biomass were obtained as well. Summaries of plots and weighed trees are shown in Table 1.

The following notations will be used hereafter. Other notations in some particular equations will be listed with those equations:

$D B H$ is diameter at breast height over bark (1.3 $\mathrm{m}$ above the ground, $\mathrm{cm})$

$H$ is total tree height (m)

$d^{2} h$ is equal to $D B H * D B H * H$

$W i$ (model) is biomass $(\mathrm{kg}$ ) for each component ( $i$ can be wood, bark, branch, foliage, root, stem, crown, total aboveground and total tree)

$t W i$ (model) is transformed biomass for each component by the Box-Cox method ( $i$ can be wood, bark, branch, foliage, root, stem, crown, total aboveground and total tree)

$p$-value in the following tables is probability of type I error in Shapiro Wilks test.

"Ime" is a linear mixed effects model

"Im" is a linear model

"sums of lme" is a method of sums of linear mixed effects model to force additivity of biomass models

"sums of lm" is a method of sums of linear model to force additivity of biomass models

SUR is a method of seemingly unrelated regressions to force additivity of biomass models

Table 1 Summary of plots and weighed trees

\begin{tabular}{|c|c|c|c|c|}
\hline \multirow[b]{2}{*}{ Items } & \multicolumn{2}{|l|}{ Natural forests (67 trees) } & \multicolumn{2}{|l|}{ Plantations (33 trees) } \\
\hline & Type or interval & $\begin{array}{l}\text { Number of } \\
\text { trees }\end{array}$ & Type or interval & $\begin{array}{c}\text { Number of } \\
\text { trees }\end{array}$ \\
\hline \multirow{7}{*}{$\begin{array}{l}\text { Site } \\
\text { type }\end{array}$} & $\begin{array}{c}\text { Sunny slope with medium or thick soil in the } \\
\text { low-elevation area }\end{array}$ & 25 & $\begin{array}{l}\text { Sunny slope with medium or thick soil } \\
\text { in the low-elevation hilly }\end{array}$ & 9 \\
\hline & $\begin{array}{l}\text { Sunny slope with thin soil in the } \\
\text { low-elevation area }\end{array}$ & 9 & $\begin{array}{l}\text { Sunny slope with thin soil in the } \\
\text { low-elevation hilly }\end{array}$ & 11 \\
\hline & $\begin{array}{l}\text { Shady slope with medium or thick soil in the } \\
\text { low-elevation area }\end{array}$ & 18 & $\begin{array}{l}\text { Shady slope with medium or thick soil } \\
\text { in the low-elevation hilly }\end{array}$ & 10 \\
\hline & $\begin{array}{l}\text { Shady slope with thin soil in the } \\
\text { low-elevation area }\end{array}$ & 7 & $\begin{array}{l}\text { Shady slope with thin soil in the } \\
\text { low-elevation hilly }\end{array}$ & 3 \\
\hline & $\begin{array}{l}\text { Flat ground with thick soil in the } \\
\text { low-elevation area }\end{array}$ & 3 & & \\
\hline & $\begin{array}{l}\text { Sunny slope with medium or thick soil in the } \\
\text { low-and middle- elevation area }\end{array}$ & 1 & & \\
\hline & $\begin{array}{l}\text { Shady slope with thin soil in the low-and } \\
\text { middle- elevation area }\end{array}$ & 4 & & \\
\hline \multirow{4}{*}{$\begin{array}{c}\text { Age } \\
\text { group } \\
\text { (years) }\end{array}$} & Small age-aged stands $(<40)$ & 38 & Small age-aged stands $(<20)$ & 4 \\
\hline & Middle-aged stands (41-60) & 26 & Middle-aged stands (21-40) & 20 \\
\hline & Nearly mature stands (61-80) & 2 & Nearly mature stands (41-50) & 9 \\
\hline & Mature stands $(>80)$ & 1 & & \\
\hline$D B H$ & {$[5,7)$} & 1 & {$[3,5)$} & 2 \\
\hline
\end{tabular}




\begin{tabular}{lcccc}
\hline class & {$[7,9)$} & 8 & {$[5,7)$} & 2 \\
$(\mathrm{~cm})$ & {$[9,11)$} & 19 & {$[7,9)$} & 2 \\
& {$[11,13)$} & 20 & {$[9,11)$} & 3 \\
& {$[13,15)$} & 7 & {$[11,13)$} & 14 \\
& {$[15,17)$} & 5 & {$[13,15)$} & 5 \\
& {$[17,19)$} & 1 & {$[15,17)$} & 5 \\
& {$[19,21)$} & 2 & & \\
& {$[21,23)$} & 2 & & \\
\hline
\end{tabular}

Independent biomass model construction for each component

Variable transformations: Before modeling, some explanatory and response variables $(V$ ) were transformed to new variables $(t V)$ by Box-Cox transformation to make frequency distributions of those variables $(t V)$ as close to normal distributions as possible. Equation (1) expresses a Box-Cox transformation (Sakia, 1992):

$t V= \begin{cases}\frac{V^{\lambda}-1}{\lambda} & \lambda \neq 0 \\ \log _{e} V & \lambda=0\end{cases}$

Where, $V$ was the original response or explanation variable (e.g., $D, H, d^{2} h$ and $\left.W i\right), t V$ was the response or explanatary variable after Box-Cox transformation (e.g., $t D, t H, t d^{2} h$ and $t W i$ ), $\lambda$ was the parameter in the Box-Cox transformation.

In this study, only variables in bark biomass models were transformed by the logarithmic transformation in above formula, while variables in other models were transformed by Box-Cox transformations with a value of $\lambda$ not equal to 0 .

Model structure and selection: Linear mixed effects models (with site as a random factor) and linear models were used to establish independent component biomass models. Variables $t D, t H, t d^{2} h, D_{l}$ were chosen as possible explanatory variables where dummy variable $D_{l}$ was introduced in a model to define forest origin $\left(D_{l}=1\right.$ for natural forests; $D_{l}=0$ for plantation). Variables $t W i$ were response variables. Model forms were (Peng and Lu, 2012; Su et al., 2012):

$$
\begin{aligned}
& Y=X \beta+Z u+e \\
& Y=X \beta+e
\end{aligned}
$$

Where, formula (2) is a linear mixed effects model; formula (3) is a linear model ; $Y$ is the vector of the response variable (e.g., $t W i) ; X$ is the vector of fixed-effect regressors (e.g., $\left.t D, t H, t d^{2} h, D_{l}\right) ; Z$ is the vector of random-effect regressors (e.g., site); $\beta$ is the vector of fixed effect coefficients (e.g., a, $\mathrm{b}, \mathrm{c}, \mathrm{e}) ; u$ is the vector of the random- effect coefficients; $e$ is the vector of errors.

For variable selection of independent component models, an overall merit-based method was used. All the regression equations in different combinations of $t D, t H, t d^{2} h, D_{l}$ were compared by examining coefficients of determination $\left(r^{2}\right)$ and root mean square errors (Rmse). Residual distribution homogeneity and model bias were visually checked by residual plots with loess regression lines overlaid on the plots. For an unbiased model, a loess line should be flat and located at the zero value on 
the vertical axis in the residual plot (Jacoby, 2000). Normality of residuals was checked with histograms of residuals and by using a Shapiro Wilk test (probabilities of type I error or p values below 0.05 indicate a departure from a normal distribution). For each biomass component an "optimal" regression equation of each component $(t W i)$ was selected. The optimal Wi model was also obtained by back-transforming the $t W i$ model and then residuals were further examined.

Compatible biomass model establishment

After obtaining independent biomass models of each component, three sets of compatible biomass models for cork oak natural forest and plantation in North China were established and compared including: (1) a total biomass regression function defined as the sum of the separately calculated best linear mixed effects models of the biomass of its components (sums of lme); (2) a total biomass regression function defined as the sum of the separately calculated best linear models of the biomass of its components (sums of $1 \mathrm{~m}$ ); and (3) simultaneous equations of linear models based on seemingly unrelated regressions (SUR). The following relationship should be satisfied (Fig.1).

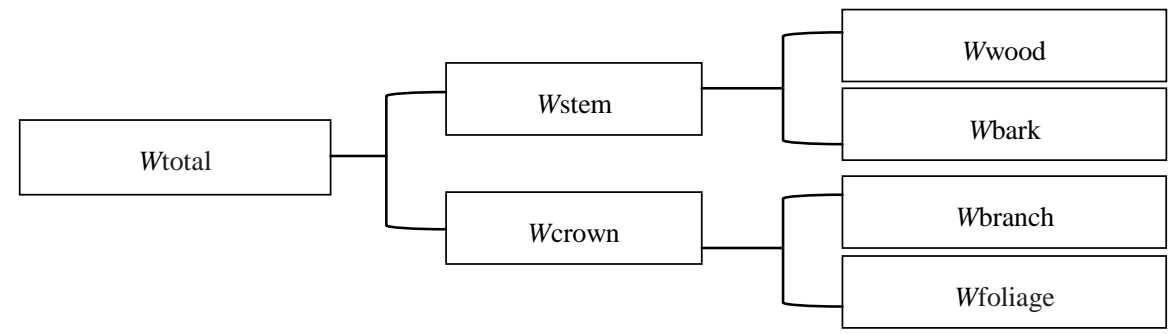

Fig. 1 Relationship between each component, where lines from right to left indicate summation

Methods (1) and (2), sums of lme and sums of lm, included stem wood biomass models, bark biomass models, branch biomass models, foliage biomass models and root biomass models. Then summing stem wood biomass models and bark biomass models to get stem biomass models, summing branch biomass models and foliage biomass models to get crown biomass models, and summing stem wood biomass models, bark biomass models, branch biomass models and foliage biomass models to get total aboveground biomass models for all the 100 trees. For 32 trees, tree total biomass models were also obtained by summing stem wood biomass models, bark biomass models, branch biomass models, foliage biomass models and root biomass models.

For method (3), simultaneous equations (based on linear models) were established with the estimated value of stem biomass of an independent linear stem biomass model (Xu, 1998). The remaining parameters in other models were jointly estimated by seemingly unrelated regressions (SUR). Given the limited number of sampled trees for root biomass, the root biomass model was not included in compatible models estimated using this method. Method (3) is described as formulae (4)-(9), where $W i$ is observed biomass value, $W_{\mathrm{i}}{ }^{\prime}$ is estimated biomass value, the $f_{\mathrm{i}}(x)$ has the same form as that in the corresponding independent biomass model:

Group1:

$W$ total aboveground $=W$ stem $^{\prime}+f$ crown $(x)$

$W$ crown $=f$ crown $(x)$

Group2:

$W$ wood $=f$ wood $(x)$

Wbark $=W$ stem $^{\prime}-f$ wood $(x)$

Group3: 
$W$ foliage $=f$ foliage $(x)$

Wbranch $=W$ crown' $^{\prime}-f$ foliage $(x)$

The parameters of the total aboveground biomass model and the crown biomass model were jointly estimated based on the estimated stem biomass using an independent stem biomass model (Group1). Then models of stem wood and bark, foliage and branch were separately jointly fitted based on the estimated stem biomass and crown biomass (Group2 and Group3). Whether or not to include any particular estimated parameter was decided by the significance of a t-test.

After establishing three sets of compatible biomass models using the three approaches, the values of $r^{2}$ and Rmse were compared. Residual distribution homogeneity and model bias were visually checked by residual plots with loess regression lines overlaid on the plots; Normality of residuals was checked with Shapiro Wilks tests and by examining histograms of residuals. Then the most suitable set of compatible biomass models could be selected.

Since an independent validation data set was not available, the Leave-One-Out Jackknife method with PRESS (Prediction Sum of Squres) statistics was used to further test those most suitable models (Sánchez-González et al., 2007; Sánchez-González et al., 2005). MPRESS (the mean of the PRESS residuals see formula (10)) and MPRESS (the mean of the absolute values of the PRESS residuals) for each $t W i$ model were computed. Additionally, the residual ranges and prediction ranges of $t W i$ models and their corresponding jackknife tests were compared with residual plots.

PRESS $=\sum_{i=1}^{n}\left(y_{i}-\widehat{y}_{i-1}\right)^{2}$

Where, $y_{i}$ is the observed value of observation $i, \widehat{y}_{i-1}$ is the estimated value for observation $i$ in a model fitted without this observation, $n$ is the number of observations.

\section{Results}

Independent biomass models of each component

The dummy variable in this study specified stand origin. Fig. 2 is a plot of the dependent variable $(t W w o o d)$ versus the independent variable $(t D B H)$ with loess regression lines overlaid on it for stem wood biomass model and suggests that there was a difference between the relationships between $t W w o o d$ and $t D B H$ for natural forest (dotted line) and plantation (solid line). Similar differences were also found for other component biomass models. The dummy variable $D_{l}$ was significant $(\mathrm{P}<0.05)$ in stem wood biomass models and foliage biomass models, which suggested that the two component models were indeed different between plantation and natural forest. While the coefficients of varable $D_{l}$ for other components models were not significant, so variable $D_{l}$ was not introduced to those models (see $t W_{\mathrm{i}}$ model in Tables 2 and 3).

The original root biomass dataset assembled 32 sets of data available in north China. However the biggest tree was an outlier (Fig.3). In order to establish a more accurate root biomass model for trees with more common sizes, the root biomass data of the biggest tree was excluded from modeling.

The best $t W_{i}$ models of various components separately based on linear mixed effects models and linear models for individual biomass components of cork oak forest were selected. Summaries of those selected models are shown in Tables 2 and 3. 
Most of the values of $r^{2}$ of the two sets of $t W i$ models were above 0.9 (Tables 2 and 3). Most of the values of $r^{2}$ of $W i$ models were above 0.8 except for bark biomass model and foliage biomass model. All the values of Rmse of Wi models were below $8 \mathrm{~kg}$.

For "Ime" $t W i$ models, probabilities of type I errors for biomass models of branch and root were above 0.05 and those for stem wood, bark and foliage were below 0.05 ; For " $1 \mathrm{~m}$ " $t W i$ models probabilities of type I errors for models of bark, branch and root were above 0.05 and those for stem wood and foliage were below 0.05 . For "lme" Wi models and "lm" Wi models, all the probabilities of type I errors were below 0.01 (Tables 2 and 3).

As the loess curves of "lme" models were much closer to the baseline than those of "lm" models, only "Ime" model residual plots and histograms of residuals for stem wood biomass model and root biomass model are shown in Fig.4 (Those for biomass models of bark, branch and foliage were quite similar and so they are not shown here). Residual ranges and predicted value ranges of "lme" models of various components are shown in Table 2. Heteroskedasticity of $t$ Wi models for "lme" was not obvious and for most of the models (Fig. 4a, c), and residuals approximately followed a normal distribution (Fig. 4b, d).

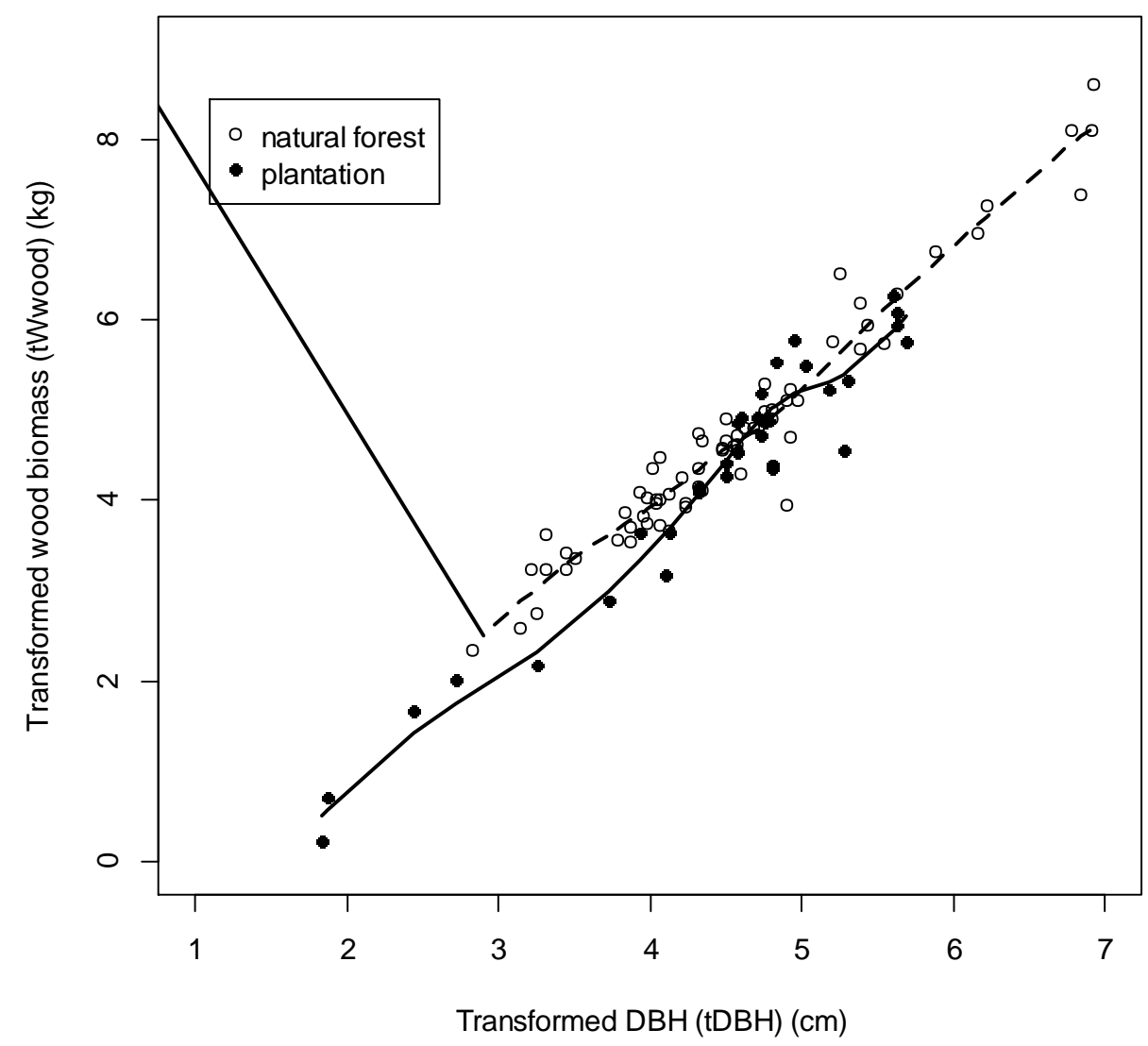

Fig. 2 Transformed stem wood biomass ( $t$ Wwood) versus transformed $D B H(t D B H)$ for stem wood biomass model (The dotted line and solid line are respectively the loess regression lines for natural forest and plantation) 


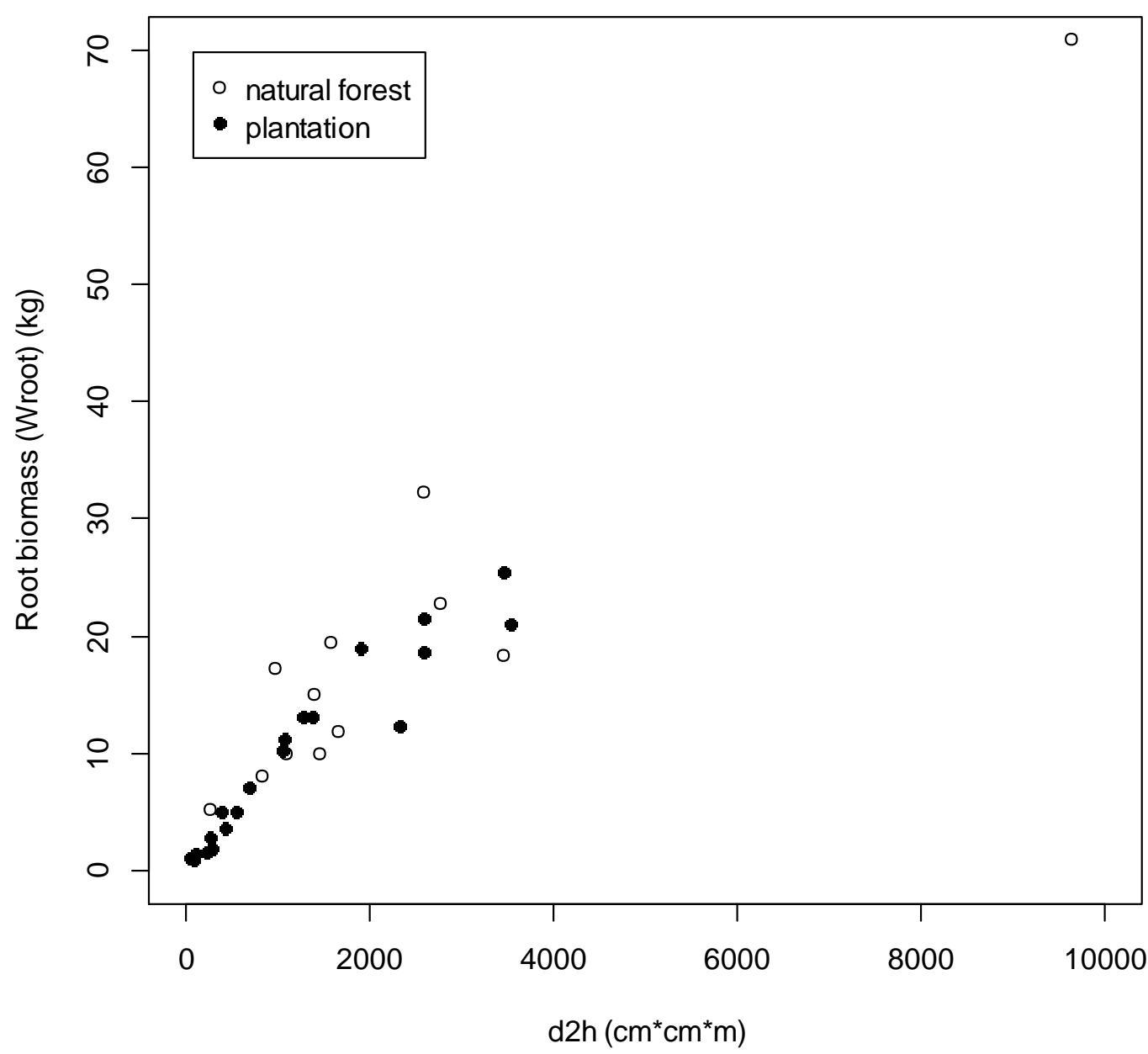

Fig. 3 Root biomass versus $d^{2} h$ for 32 sets of data

Table 2 Summary for independent biomass linear mixed effects models (lme)

\begin{tabular}{|c|c|c|c|c|c|c|c|c|}
\hline$t W_{\mathrm{i}}$ model & $\begin{array}{c}p \text {-value } \\
(t \text { Wi })\end{array}$ & $\begin{array}{c}r^{2} \\
(t W i)\end{array}$ & $\begin{array}{l}\text { Rmse } \\
(t W i)\end{array}$ & $\begin{array}{c}p \text {-value } \\
\text { (Wi) }\end{array}$ & $\begin{array}{c}r^{2} \\
(W i)\end{array}$ & $\begin{array}{r}\text { Rmse } \\
(W i)\end{array}$ & $\begin{array}{c}\text { predicted } \\
\text { value range }\end{array}$ & $\begin{array}{c}\text { Residual } \\
\text { range }\end{array}$ \\
\hline $\begin{array}{c}t W w o o d=a+b * t D B H \\
+c * D_{l}\end{array}$ & 0.020 & 0.959 & 0.283 & $1.677 \mathrm{e}-08$ & 0.958 & 7.645 & $(0.2,8.2)$ & $(-1.5,0.7)$ \\
\hline$t$ Wbark $=a+b * t D B H$ & 0.002 & 0.903 & 0.223 & $<2.2 \mathrm{e}-16$ & 0.706 & 5.577 & $(-0.1,3.8)$ & $(-1.0,0.9)$ \\
\hline $\begin{array}{c}t \text { Wbranch }=a+b * t d^{2} h+ \\
c * H\end{array}$ & 0.842 & 0.902 & 0.360 & $4.433 \mathrm{e}-11$ & 0.898 & 4.876 & $(-0.3,5.5)$ & $(-1.0,1.0)$ \\
\hline $\begin{array}{c}t \text { Wfoliage }=a+b * H+ \\
c^{*} t d 2 h+e^{*} D_{l}\end{array}$ & 0.011 & 0.780 & 0.361 & $1.315 \mathrm{e}-05$ & 0.748 & 1.105 & $(-0.6,2.7)$ & $(-1.0,0.8)$ \\
\hline$t$ Wroot $=a+b * t d 2 h$ & 0.097 & 0.884 & 0.696 & 0.005232 & 0.839 & 1.824 & $(-0.8,11.0)$ & $(-2.2,3.6)$ \\
\hline$t W_{\mathrm{i}}$ model & & $\begin{array}{r}p \text {-val } \\
\left(t W_{i}\right.\end{array}$ & & & & $\begin{array}{c}p \text {-value } \\
\left(W_{i}\right)\end{array}$ & $r^{2}\left(W_{\mathrm{i}}\right)$ & $\begin{array}{l}\text { Rmse } \\
\left(W_{\mathrm{i}}\right)\end{array}$ \\
\hline
\end{tabular}




\begin{tabular}{ccccccc}
\hline$t$ Wwood $=a+b * t D B H+c^{*} D_{l}$ & 0.022 & 0.944 & 0.332 & $8.697 \mathrm{e}-10$ & 0.936 & 9.381 \\
$t$ Wbark $=a+b * t D B H$ & 0.126 & 0.875 & 0.253 & $1.048 \mathrm{e}-15$ & 0.689 & 5.739 \\
$t$ Wbranch $=a+b * t d 2 h+c * H$ & 0.889 & 0.874 & 0.409 & $4.544 \mathrm{e}-12$ & 0.861 & 5.689 \\
$t$ Wfoliage $=a+b * H+c * t d^{2} h+e^{*} D_{l}$ & 0.009 & 0.768 & 0.371 & $1.116 \mathrm{e}-05$ & 0.732 & 1.139 \\
$t$ Wroot $=a+b * t d 2 h$ & 0.079 & 0.864 & 0.756 & 0.005085 & 0.811 & 1.979 \\
\hline
\end{tabular}

a

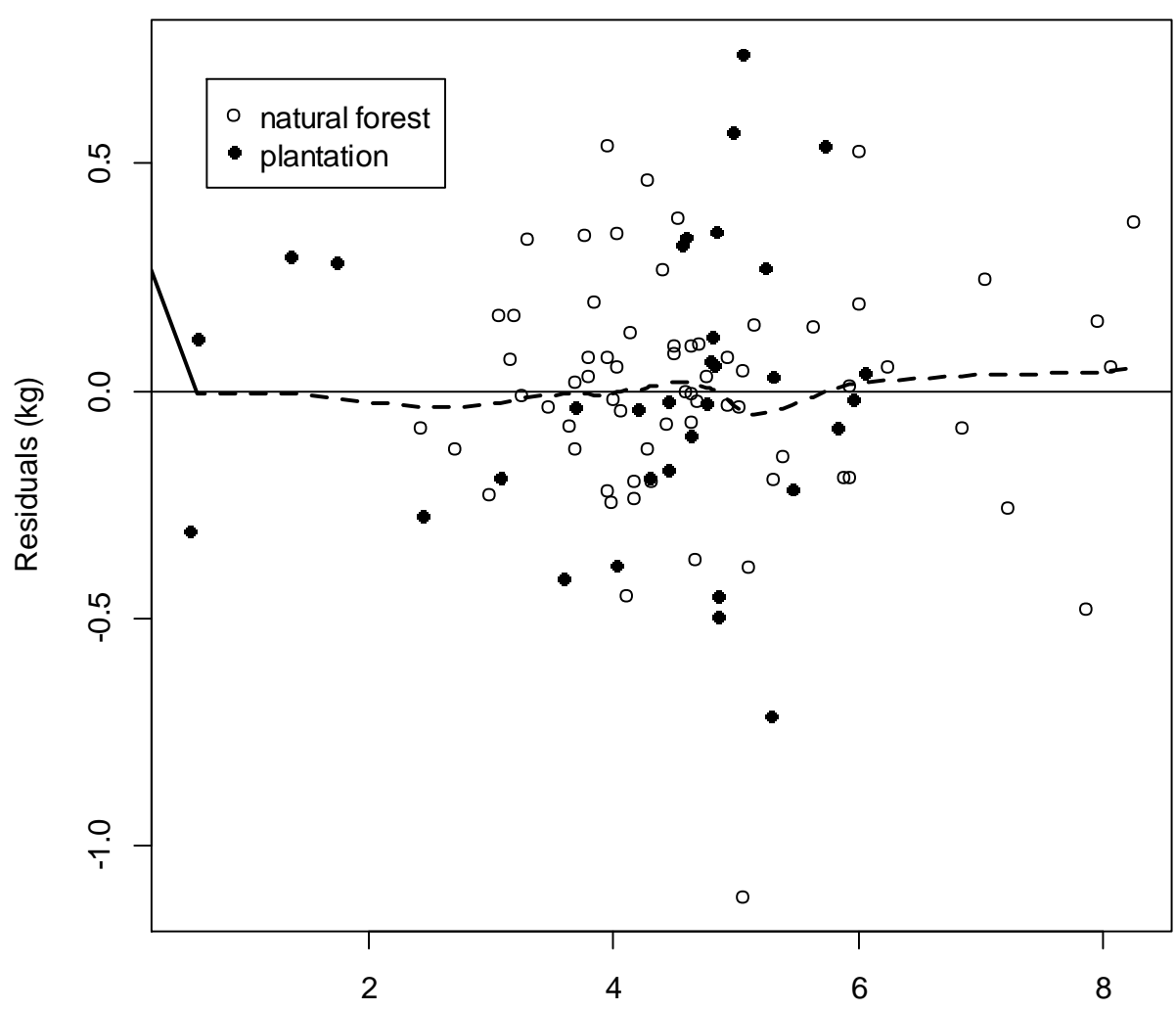

Fitted values of transformed wood biomass model (tWwood) $(\mathrm{kg})$ 
b

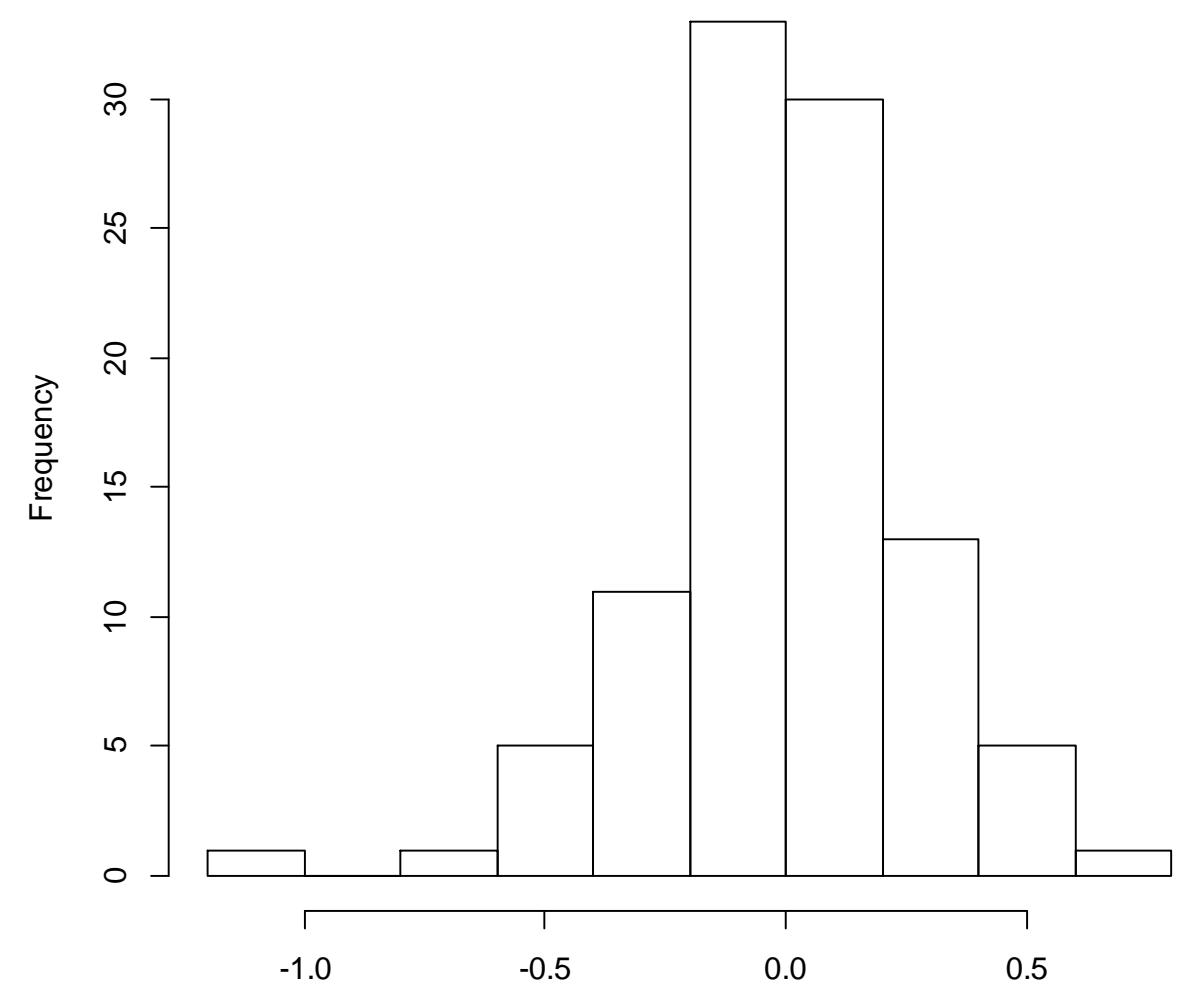

Residuals of transformed wood biomass model (tWwood) (kg) 


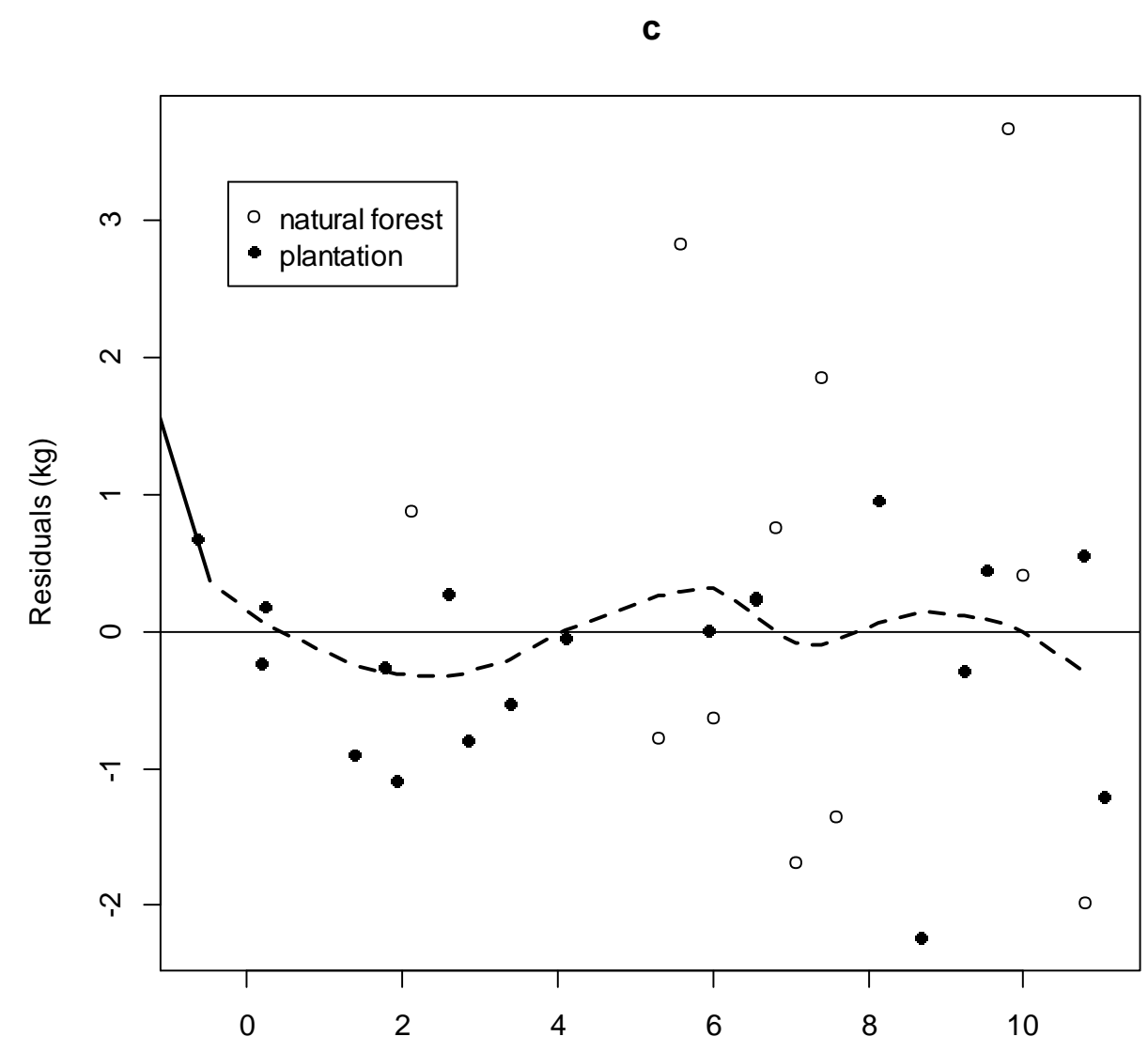

Fitted values of transformed root biomass model (tWroot) (kg) 


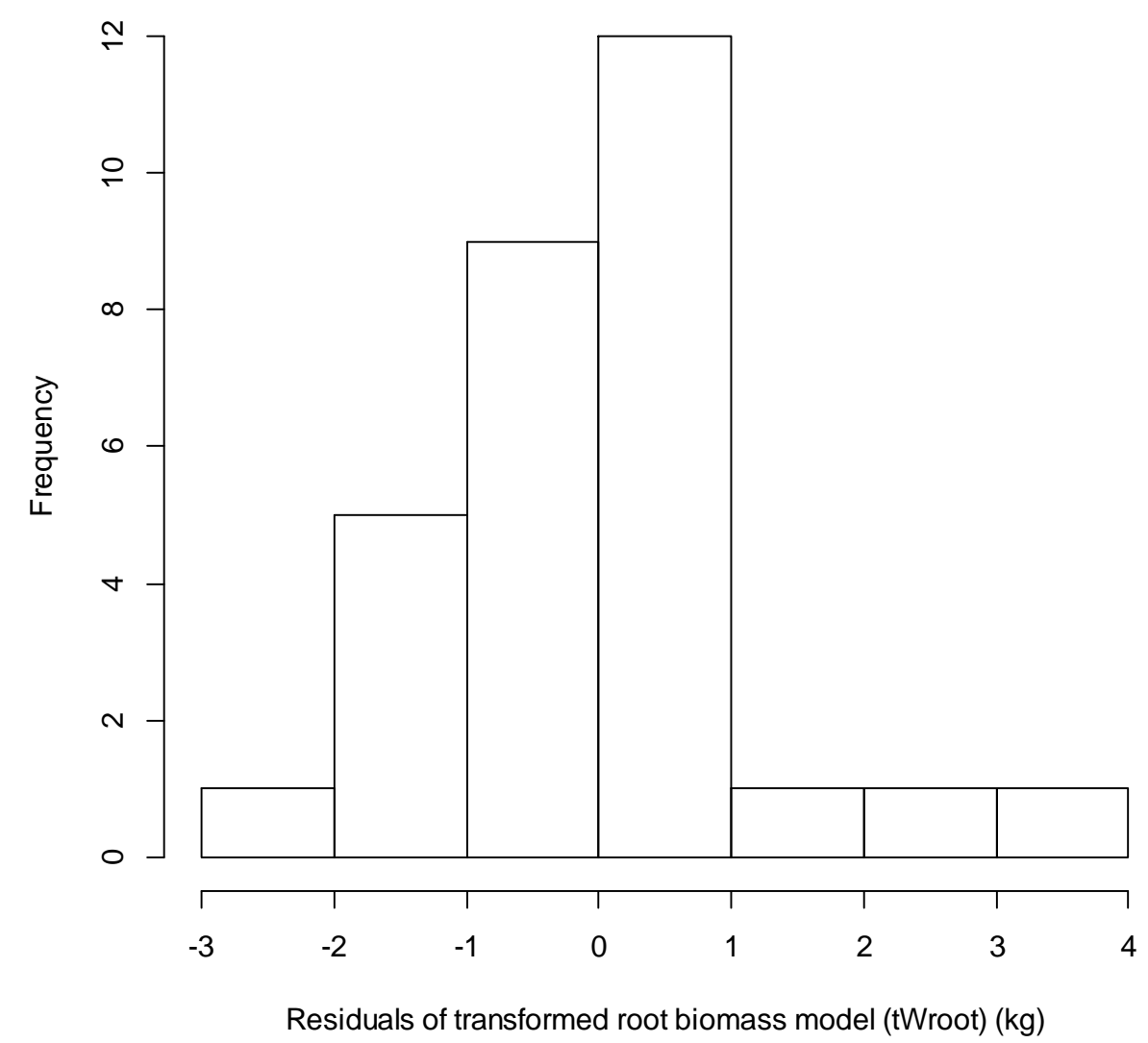

Fig.4 Loess residual plots and histograms of residuals for independent biomass linear mixed effects models (lme) (For Fig. 4a, c, the solid horizontal lines are baselines and the dotted lines are loess curves)

Compatible biomass models

Coefficients and standard errors of the coefficients for the three sets of compatible biomass models ((1) sums of lme; (2) sums of $1 \mathrm{~m}$; and (3) SUR) are listed in Table 4.

The corresponding probabilties of type I errors in Shapiro Wilk tests ( $p$-value) for "sums of lme" and "sums of $1 \mathrm{~m}$ " are in Table 5. The corresponding values for SUR are in Table 6.

Table 4 Coefficients and standard errors of the coefficients (se) for "sums of lme", "sums of 1m" and SUR (Wi)

\begin{tabular}{|c|c|c|c|c|c|}
\hline \multirow{2}{*}{$\begin{array}{c}\text { Components } \\
\text { (equation form and } \lambda(i) \text { ) }\end{array}$} & \multirow{2}{*}{ Methods } & \multicolumn{4}{|c|}{ Coefficients $( \pm s e)$} \\
\hline & & $a( \pm s e)$ & $b( \pm s e)$ & $c( \pm s e)$ & $e( \pm s e)$ \\
\hline stem & SUR & $\begin{array}{l}-1.776^{* * *} \\
( \pm 0.121)\end{array}$ & $\begin{array}{l}0.481^{* * *} \\
( \pm 0.009)\end{array}$ & & \\
\hline stem wood & Sums of & $-1.710^{* * *}$ & $1.3449^{* * *}$ & $0.3909^{* *}$ & \\
\hline$\left(t W w o o d=a+b * t D B H+c^{*} D_{l}\right.$ & lme & $( \pm 0.229)$ & $( \pm 0.0459)$ & $( \pm 0.1369)$ & \\
\hline$\lambda(W w o o d)=0.16$ & Sums of & $-1.995^{* * *}$ & $1.418^{* * *}$ & $0.249^{* * *}$ & \\
\hline$\lambda(D B H)=0.45)$ & $\operatorname{lm}$ & $( \pm 0.167)$ & $( \pm 0.036)$ & $( \pm 0.071)$ & \\
\hline bark & Sums of & $-2.687^{* * *}$ & $2.000^{* * *}$ & & \\
\hline$\left(t\right.$ Wbark $=a+b^{*} t D B H$ & lme & $( \pm 0.230)$ & $( \pm 0.092)$ & & \\
\hline
\end{tabular}




\begin{tabular}{|c|c|c|c|c|c|}
\hline$\lambda($ Wbark $)=0$, & Sums of & $-2.865^{* * *}$ & $2.065^{* * *}$ & & \\
\hline$\lambda(D B H)=0)$ & $\operatorname{lm}$ & $( \pm 0.194)$ & $( \pm 0.079)$ & & \\
\hline & SUR & $\begin{array}{l}-3.558^{* * *} \\
( \pm 0.277)\end{array}$ & $\begin{array}{l}2.336^{\text {*** }} \\
( \pm 0.097)\end{array}$ & & \\
\hline crown & SUR & $\begin{array}{l}-2.300^{* * *} \\
( \pm 0.200)\end{array}$ & $\begin{array}{l}-0.086^{* *} \\
( \pm 0.029)\end{array}$ & $\begin{array}{l}0.453^{* * *} \\
( \pm 0.031)\end{array}$ & \\
\hline branch & Sums of & $-2.988^{* * *}$ & $0.563^{* * *}$ & $-0.194^{* * *}$ & \\
\hline$(t$ Wbranch $=a+b * t d 2 h+c * H$ & lme & $( \pm 0.286)$ & $( \pm 0.039)$ & $( \pm 0.041)$ & \\
\hline$\lambda($ Wbranch $)=0.11$, & Sums of & $-2.911^{* * *}$ & $0.560^{* * *}$ & $-0.197^{* * *}$ & \\
\hline$\left.\lambda\left(d^{2} h\right)=0.16\right)$ & $\operatorname{lm}$ & $( \pm 0.221)$ & $( \pm 0.039)$ & $( \pm 0.043)$ & \\
\hline & Sums of & $-2.126^{* * *}$ & $-0.122^{* *}$ & $0.349^{* * *}$ & $-0.311^{* *}$ \\
\hline foliage & lme & $( \pm 0.220)$ & $( \pm 0.039)$ & $( \pm 0.036)$ & $( \pm 0.096)$ \\
\hline$\left(t\right.$ Wfoliage $=a+b * H+c * t d^{2} h+e^{*} D_{I}$ & Sums of & $-2.091^{* * *}$ & $-0.126^{* *}$ & $0.350^{* * *}$ & $-0.289^{* * *}$ \\
\hline$\lambda($ Wfoliage $)=0.18$ & $\operatorname{lm}$ & $( \pm 0.204)$ & $( \pm 0.039)$ & $( \pm 0.035)$ & $( \pm 0.079)$ \\
\hline$\left.\lambda\left(d^{2} h\right)=0.16\right)$ & SUR & $\begin{array}{l}-2.077^{\text {*** }} \\
( \pm 0.201)\end{array}$ & $\begin{array}{l}-0.086^{* *} \\
( \pm 0.033)\end{array}$ & $\begin{array}{l}0.318^{* * *} \\
( \pm 0.033)\end{array}$ & $\begin{array}{l}-0.252^{* * *} \\
( \pm 0.067)\end{array}$ \\
\hline root & Sums of & $-2.058^{* *}$ & $0.185^{* * *}$ & & \\
\hline$\left(t\right.$ Wroot $=a+b * t d^{2} h$ & lme & $( \pm 0.763)$ & $( \pm 0.016)$ & & \\
\hline$\lambda($ Wroot $)=0.66$ & Sums of & $-2.287^{* *}$ & $0.190^{* * *}$ & & \\
\hline$\left.\lambda\left(d^{2} h\right)=0.42\right)$ & $\operatorname{lm}$ & $( \pm 0.643)$ & $( \pm 0.014)$ & & \\
\hline
\end{tabular}

Significant codes: ${ }^{* * *} 0.001,{ }^{* *} 0.01,{ }^{*} 0.05$. The type III sums of squares were used in "sums of $1 m e$ " and "sums of $1 \mathrm{~m}$ ". The t-tests were used in SUR.

Table 5 -value in Shapiro Wilks test for sums of lme and sums of $1 \mathrm{~m}$

\begin{tabular}{ccc}
\hline Wi model & sums of $1 \mathrm{me}$ & sums of $1 \mathrm{~m}$ \\
\hline $\begin{array}{c}t \text { Wstem }=t \text { Wwood }+t \text { Wbark } \\
t \text { Wcrown }=t \text { Wbranch }+t \text { Wfoliage } \\
t \text { Wtotal aboveground }=t \text { Wwood }+t \text { Wbark+ } \\
t \text { Wbranch }+t \text { Wfoliage }\end{array}$ & $2.643 \mathrm{e}-12$ & $8.645 \mathrm{e}-13$ \\
$t$ Wtotaltree $=t$ Wwood $+t$ Wbark $+t$ Wbranch $+t$ Wfoliage $+t$ Wroot & $2.503 \mathrm{e}-11$ & $7.41 \mathrm{e}-12$ \\
& $1.552 \mathrm{e}-13$ & $7.998 \mathrm{e}-14$ \\
\hline
\end{tabular}

Table $6 r^{2}$, Rmse and $p$-value in Shapiro Wilks tests for simultaneous equations (SUR)

\begin{tabular}{ccccc}
\hline & Simultaneous equations based on $1 \mathrm{~m}$ & $r^{2}$ & Rmse & p-value $($ Wi $)$ \\
\hline \multirow{3}{*}{ Group1 } & Wstem & 0.954 & 9.990 & $8.349 \mathrm{e}-13$ \\
& Wcrown & 0.893 & 5.560 & $3.88 \mathrm{e}-07$ \\
\multirow{2}{*}{ Group2 } & Wtotal aboveground $=$ Wstem + Wcrown & 0.951 & 14.007 & $8.187 \mathrm{e}-13$ \\
& Wwood $=$ Wstem-Wbark & 0.964 & 7.020 & $7.566 \mathrm{e}-05$ \\
Group3 & Wbark & 0.719 & 5.453 & $2.354 \mathrm{e}-14$ \\
& Wbranch=Wcrown-Wfoliage & 0.894 & 4.998 & $4.986 \mathrm{e}-07$ \\
\hline
\end{tabular}

All the coefficients for the three sets of compatible biomass models were significant at $\alpha=0.01$ confidence level (Table 4). Generally speaking, standard errors for the three sets of models were very 
low compared to the magnitudes of predicted values. For sums of lme models, the values ranged from 0.016 to 0.763 (Table 4 ).

Most of the values of $r^{2}$ of Wi models in SUR were above 0.8 except for the bark biomass model and the foliage biomass model, and values of $r^{2}$ in SUR were a little larger than those of "sums of $1 \mathrm{~m}$ " models for stem wood biomass, bark biomass, branch biomass and foliage biomass (Table 3, Table 6). Most of the values of Rmse in SUR were below $10 \mathrm{~kg}$ except for the total aboveground biomass model and values of Rmse in SUR were a little smaller than those in "sums of $1 \mathrm{~m}$ " models for stem wood biomass, bark biomass, branch biomass, foliage biomass (Table 3, Table 6).

The loess curves of "sums of lme" models were closest to the x-axis, followed by "sums of lm", and SUR with the biggest deviation from the x-axis, and only "sums of lme" models residual plots and histograms of residuals for total aboveground biomass and total tree biomass are shown in Fig.5 with the same symbol meanings as Fig. 4. The loess lines of each "sums of lme" model generally produced a flat line located at the baseline except for few big trees with $D B H$ values above $19 \mathrm{~cm}$ or $H$ values above $15 \mathrm{~m}$ (Fig. 5a, c). For most of the "sums of lme" Wi models, the residuals did not follow normal distribution and heteroskedasticity was obvious (Fig. 5b, d).

To sum up, Values of $r^{2}$ were a little higher and values of Rmse were a little lower in SUR than those in "sums of lm", but SUR had higher bias than "sums of $1 \mathrm{~m}$ " for most components, and the "sums of $1 \mathrm{~m}$ " had higher bias than the "sums of lme" whose loess lines of each model generally produced a flat line located at the baseline except for few big trees (Fig. 5a, c), therefore the "sums of lme" in the three above methods was the most suitable way to force additivity of different components in this study. 


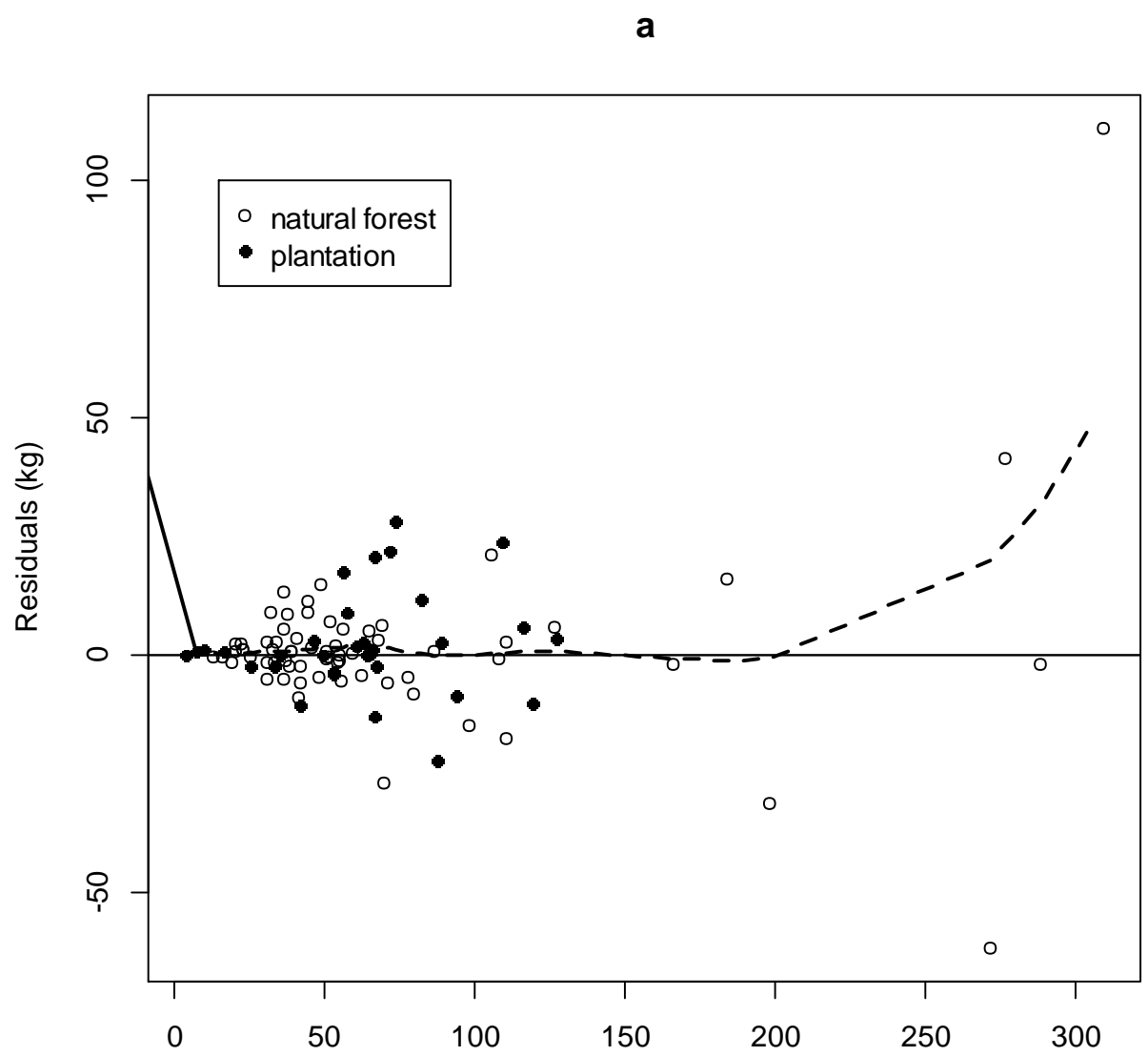

Fitted values of total aboveground biomass model (Wtotal aboveground) (kg) 


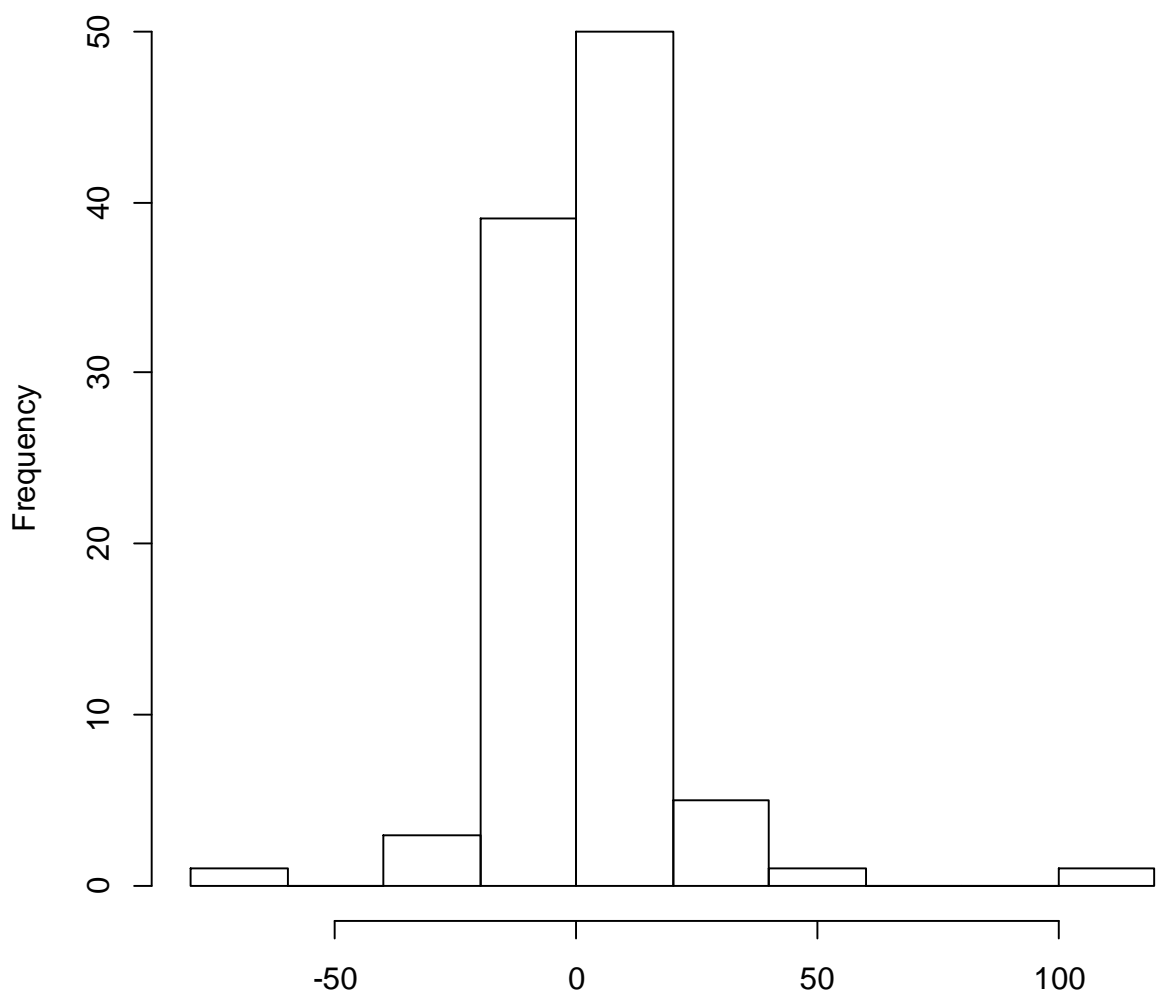

Residuals of total aboveground biomass model (Wtotal aboveground) (kg) 


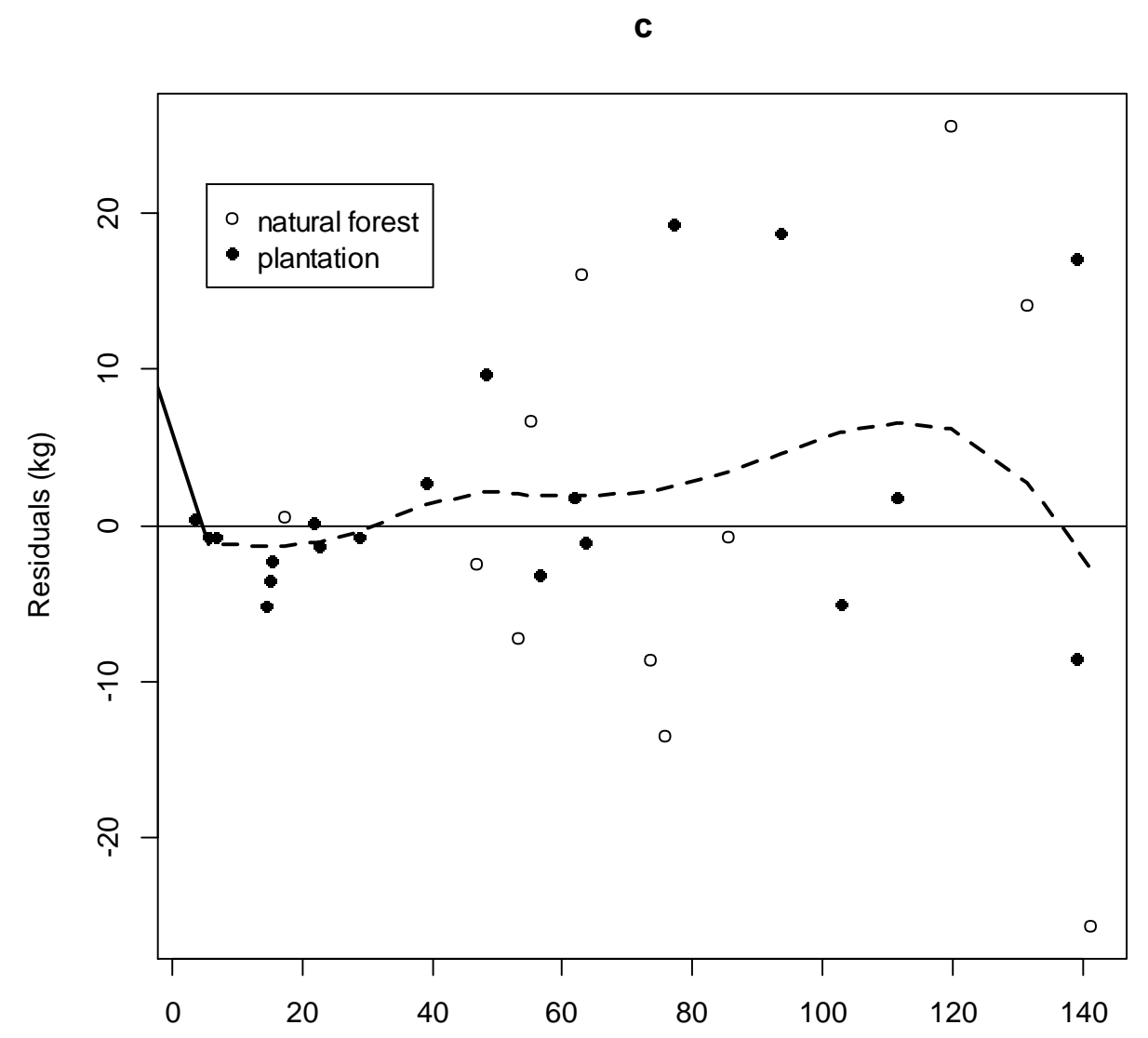

Fitted values of total tree biomass model (Wtotal tree) $(\mathrm{kg})$ 


\section{d}

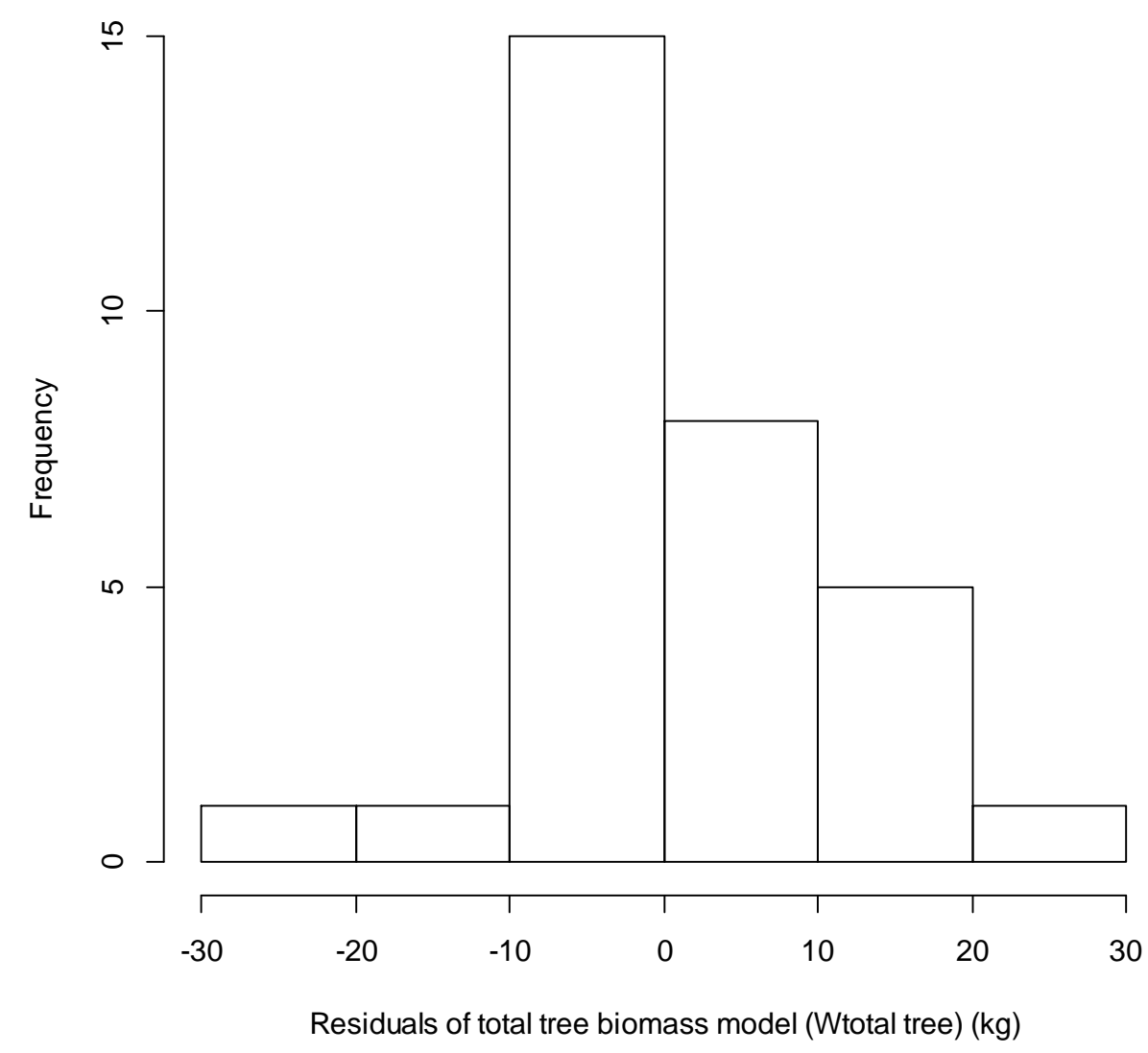

Fig. 5 Loess residual plots and histograms of residual for compatible linear mixed effects models (sums of lme)

Jackknife test and PRESS statistics of linear mixed effects models

Compatible biomass models based on the method of "sums of lme" were selected as the best models and so they were validated with jackknife methods and PRESS (Prediction Sum of Squres) statistics. The MPRESS and MAPRESS statistics for each $t W i$ model are shown in Table 7. Residual plots and histograms of residuals for the jackknife testing of stem wood biomass model and root biomass model $(t W i)$ are shown in Fig.6 with the same symbol meanings as Fig.4. Residual ranges and predicted value ranges for the jackknife tests of various components are shown in Table 7.

Table7 Summary for each "sums of lme" $t$ Wi model from jackknife fitting

\begin{tabular}{ccccccc}
\hline Component & p-value & PRESS & MPRESS & MAPRESS & $\begin{array}{c}\text { predicted value } \\
\text { range }\end{array}$ & $\begin{array}{c}\text { Residual } \\
\text { range }\end{array}$ \\
\hline stem wood & 0.057 & 9.779 & 0.0006 & 0.231 & $(0.2,8.2)$ & $(-1.5,0.7)$ \\
bark & 0.0004 & 6.333 & $-8.955 \mathrm{e}-05$ & 0.174 & $(-0.1,3.8)$ & $(-1.0,0.9)$ \\
branch & 0.820 & 15.639 & -0.003 & 0.318 & $(-0.3,5.5)$ & $(-1.0,1.0)$ \\
foliage & 0.009 & 14.682 & -0.002 & 0.284 & $(-0.6,2.7)$ & $(-1.0,0.8)$ \\
root & 0.089 & 60.481 & -0.039 & 1.111 & $(-0.8,11.0)$ & $(-2.1,4.3)$ \\
\hline
\end{tabular}




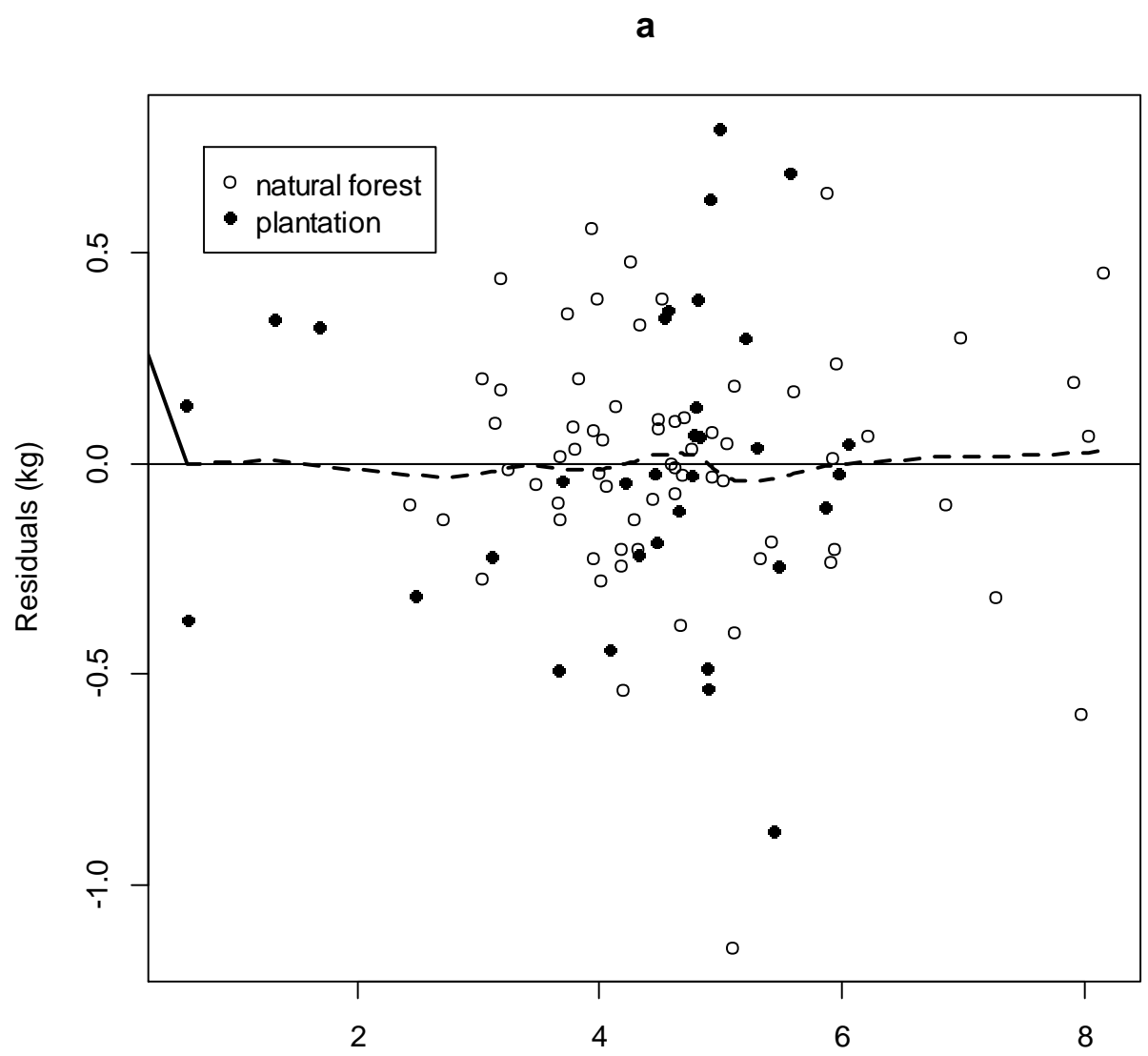

Fitted values of transformed wood biomass model from jackknife fitting (tWwood) (kg) 
b

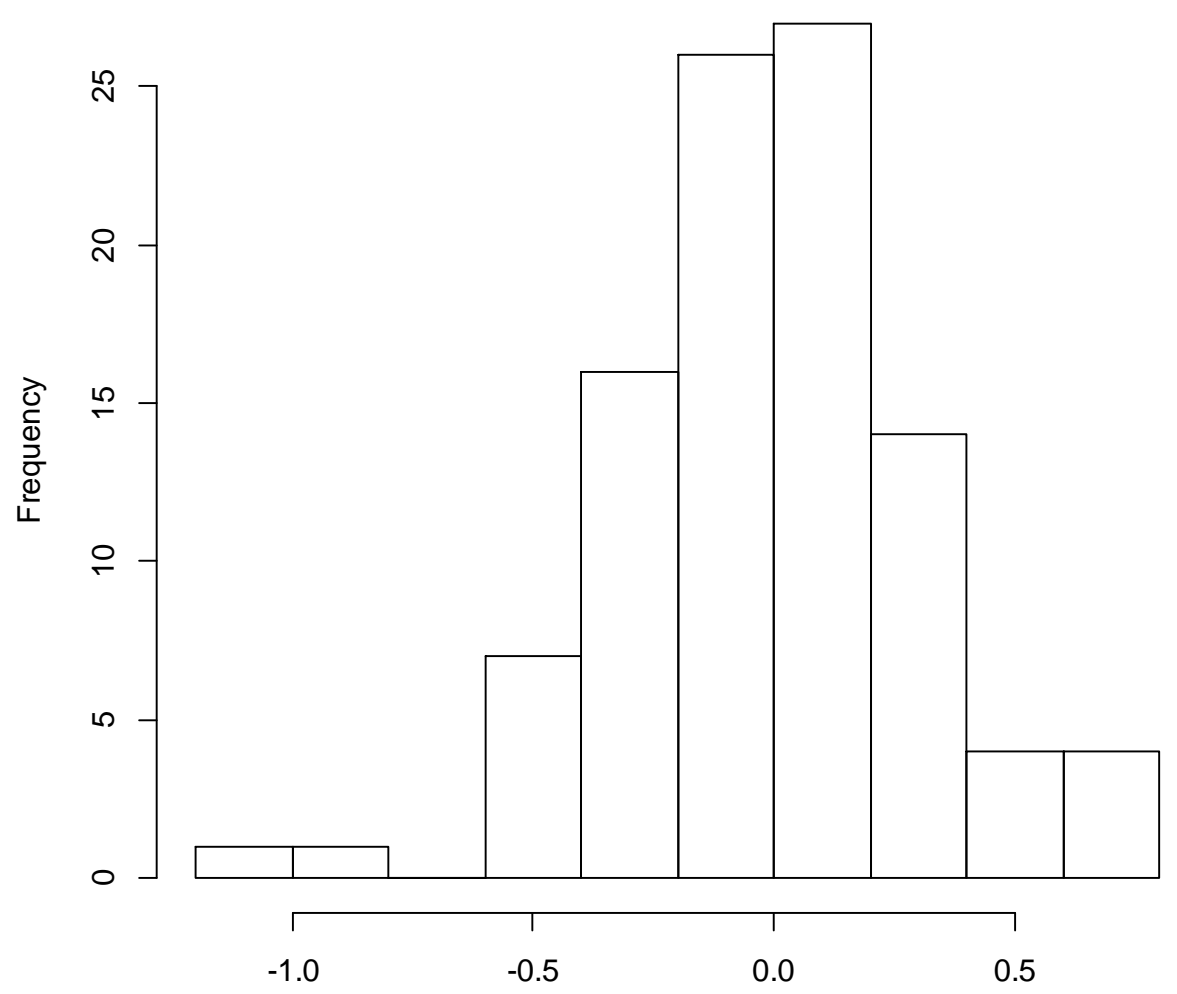

Residuals of transformed wood biomass model from jackknife fitting (tWwood) (kg) 


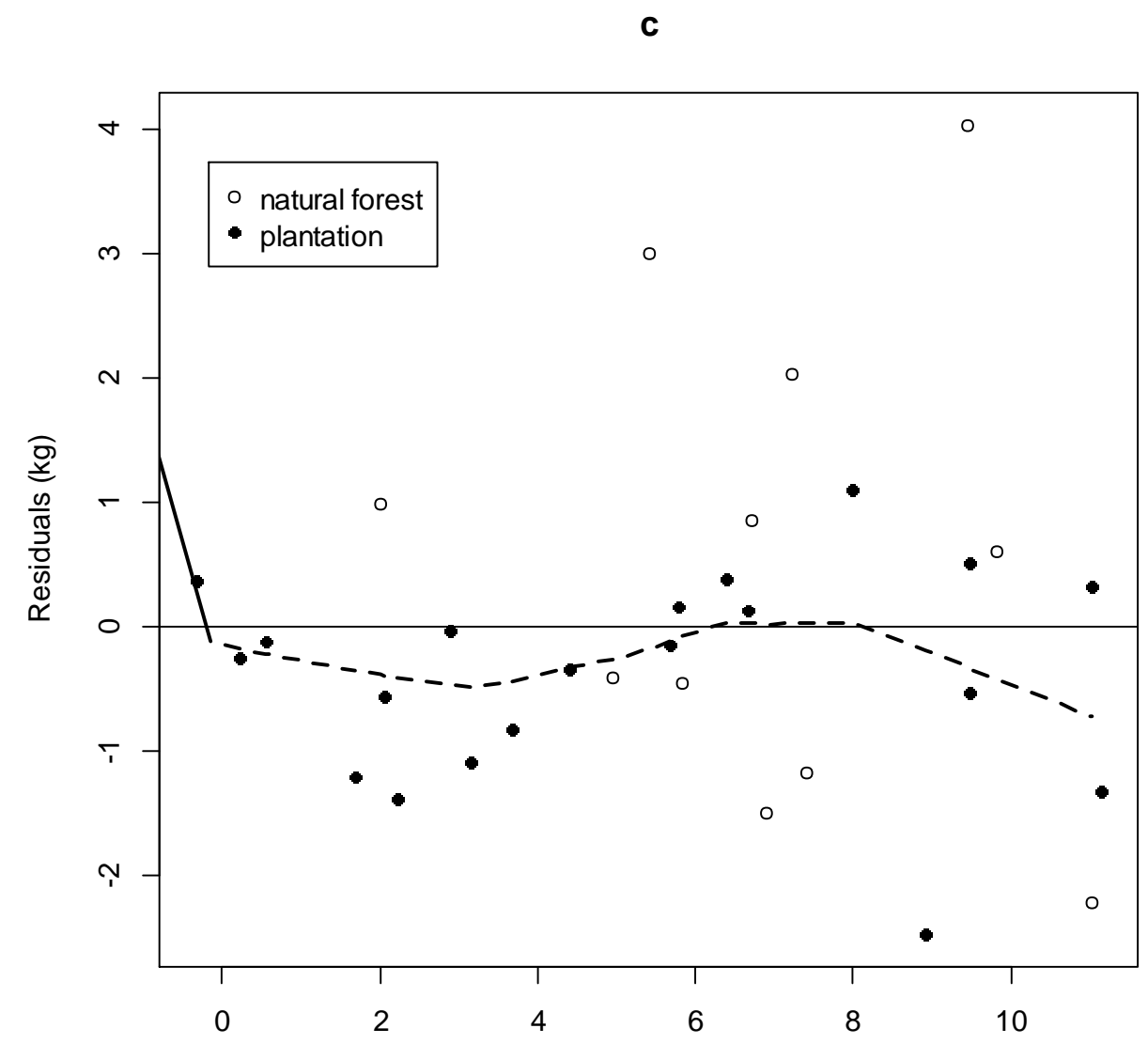

Fitted values of transformed root biomass model from jackknife fitting (tWroot) (kg) 


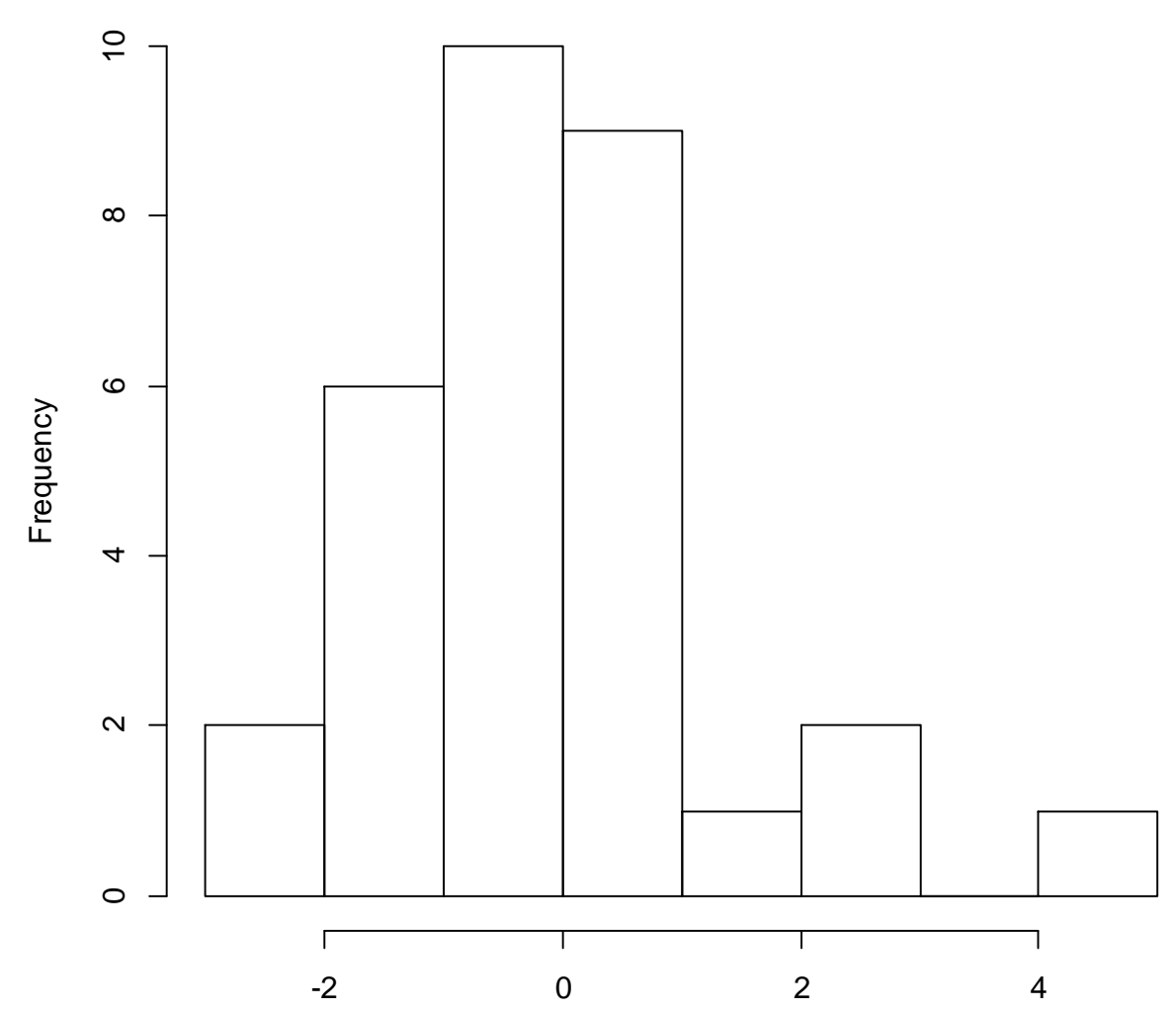

Residuals of transformed root biomass model from jackknife fitting (tWroot) (kg)

Fig.6 Residual plots and histograms of residuals for jackknife testing

Table7 shows values of PRESS, MPRESS and MAPRESS for each $t W_{i}$ model. Values of MPRESS for the stem wood biomass model, bark biomass model, branch biomass model and foliage biomass model were respectively $0.0006,-8.955 \mathrm{e}-05,-0.003$ and -0.002 ; and values of MAPRESS for the four models were respectively $0.231,0.174,0.318$ and 0.284 . Values of MPRESS and MAPRESS for the root biomass model were respectively -0.039 and 1.111 .

It can be seen from Figs.4, 6 that for the $t W i$ model the scatter distribution in residual plots from fitting and those from the jackknife validation were similar and frequency distributions in histograms of residuals were similar as well. In Fig.6a, c, heteroskedasticity was not obvious and the loess curves were close to the x-axes. In addition, residuals approximately followed normal distributions (Fig.6 b, d).

Comparing the residual ranges of biomass models of various components in Tables 2 and 7, it can seen that for stem wood biomass, bark biomass, branch biomass and foliage biomass, the residual ranges of $t W i$ models and jackknife tests were approximately equal, respectively were from -1.5 to 0.7 , from -1.0 to 0.9 , from -1.0 to 1.0 and from -1.0 to 0.8 . The predicted value ranges of above four $t W i$ models and their jackknife tests were also approximately equal, respectively were from 0.2 to 8.2 , from -0.1 to 3.8 , from -0.3 to 5.5 and from -0.6 to 2.7. For root biomass, the prediction ranges of $t W i$ models and 
jackknife tests were approximately equal, i.e., both were from -0.8 to 11.0 ; however, the residual ranges were from -2.2 to 3.6 for $t$ Wroot model and from -2.1 to 4.3 for its jackknife test.

\section{Discussion}

Selection of compatible models

Parresol $(1999,2001)$ proposed and compared two methods to force additivity of biomass models: (1) the total biomass regression function is defined as the sum of the separately calculated best regression functions of the biomass of its components; (2) joint-generalized least squares regression considerring the contemporaneous correlations among equations, like seemingly unrelated regressions (SUR). By comparing standard errors of the coefficients of the two procedures and their own confidence and prediction intervals, the author pointed out that procedure (2) was recommended over procedure (1). Other researchers also reported that system estimating methods were more flexible and directly used simultaneous methods such as two-stage least squares (2SLS), three-stage least squares (3SLS), seemingly unrelated regressions (SUR), generalized method of moments (GMM). (António et al., 2007; Balboa-Murias et al., 2006; Bi et al., 2010; Brandeis et al., 2006; Gómez-García et al., 2013; Gómez-García et al., 2014; Hasenauer et al., 1998; Carvalho and Parresol, 2003; Li and Zhao, 2013; Menéndez-Miguélez et al., 2013; Ruiz-Peinado et al., 2011). Just few researchers compared the aboving procedure (1) and procedure (2) again before using system estimating methods to fit models, e.g., (Návar et al., 2002).

However some researchers fitted biomass models using procedure (1) rather than procedure (2) to make sure of the compatibility, i.e., fitting equations firstly and then evaluating additivity of predicted biomass components (Saint-André et al., 2005; Shaiek et al., 2011).

In our study, three methods including "sums of lme", "sums of $1 \mathrm{~m}$ " and SUR were compared on $r^{2}$, Rmse and residuals plots, and the "sums of lme" in the three above methods was finally selected as the most suitable way to force additivity of different components in this study. This study may have been a special case as Parresol suggested in his paper (Parresol, 2001) that

"...if one is faced with a small sample size and if contemporaneous correlations are small, then there is a loss in finite sample efficiency with estimated generalized NSUR, In this case, procedure (1) is best".

Root biomass model and bark biomass model

The residual range for the root biomass model from fitting was a little wider than that from jackknife validation, but not overly (Figs.4, 6 c), so the root biomass model can be considered to have met the conditions for a jackknife validation. The bark biomass model used a logarithmic transformation and according some researchers (Baskerville, 1972; Wauters et al., 2008; Zianis et al., 2011), this may produce systematic underestimation of the dependent variable $\mathrm{Y}$ when converting the estimated $\log _{\mathrm{e}} \mathrm{Y}$ back to the original scale Y. A correction factor should be used to correct this bias according to those researchers. However, the correction factor was not used in this study as little bias was detected after back transformation. 


\section{Conclusions}

Biomass models obtained using the "sums of lme" method were selected as the most suitable in this study because they were less baised than those fitted using "sums of lm" or SUR methods.

Forms of the "sums of lme" $t W i$ models (with only fixed effects) were respectively $t W w o o d=a+b * t D B H+c * D_{1}, t$ Wbark $=a+b * t D B H, t$ Wbranch $=a+b * t d 2 h+c * H$, $t$ Wfoliage $=a+b * H+c * t d^{2} h+e^{*} D_{1}$ and $t$ Wroot $=a+b * t d 2 h$. Then the Wi models can be obtained by converting the estimated $t W i$ models back to the original scale Wi.

The coefficients of determination $\left(r^{2}\right)$ for the biomass models were 0.958 for the stem wood biomass model, 0.706 for the bark biomass model, 0.898 for the branch biomass model, 0.748 for the foliage biomass model and 0.839 for the root biomass model. Root mean square errors (Rmse) for those five models were respectively $7.645 \mathrm{~kg}, 5.577 \mathrm{~kg}, 4.876 \mathrm{~kg}, 1.105 \mathrm{~kg}$ and $1.824 \mathrm{~kg}$. Standard errors of the coefficients (se) of those models ranged from 0.016 to 0.763 . The residual ranges for the biomass models and their corresponding jackknife tests were approximately equal, respectively from -1.5 to 0.7 for stem wood, from -1.0 to 0.9 for bark, from -1.0 to 1.0 for branch and from -1.0 to 0.8 for foliage. The residual ranges for the root biomass model and its jackknife test were not so similar, respectively from -2.2 to 3.6 and from -2.1 to 4.3 .

Within the specific ranges of $\mathrm{DBH}(4 \mathrm{~cm}, 19 \mathrm{~cm})$ or $H(5 \mathrm{~m}, 15 \mathrm{~m})$ in the dataset used in this study, the biomass models fitted with the "sums of lme" method can be used for calculation and prediction of biomass or carbon stocks of the cork oak forests in North China.

\footnotetext{
Acknowledgements This research was jointly supported by China Scholarship Council, scientific and research base construction projects of Beijing Municipal Education Commission (SYSBL2009), forestry science promotion project of the State Forestry Bureau (2011-44), open fund project of Beijing Forestry University '985' advantage subject innovation platform (000-1108003), and special fund project for forestry public service industry and research (201004021). We acknowledge the strong support from Zhong Tiaoshan National Forest Authority, Xingtai County Forestry Bureau, Si Zuolou forestry station and Xi Shan forestry station in Beijing.
}

Conflict of interest The authors declare that they have no conflict of interest.

\section{References:}

António N, Tomé M, Tomé J, Soares P, Fontes L (2007) Effect of tree, stand, and site variables on the allometry of Eucalyptus globulus tree biomass. Canadian Journal of Forest Research 37: 895-906

Balboa-Murias MÁ, Rodríguez-Soalleiro R, Merino A, Álvarez-González JG (2006) Temporal variations and distribution of carbon stocks in aboveground biomass of radiata pine and maritime pine pure stands under different silvicultural alternatives. Forest Ecol Manag 237: 29-38

Bao X, Chen L, Chen Q, Ren J, Hu Y, Li Y (1984) Biomass of Quercus variabilis forest. Acta Phytoecologica et Geobotanica Sinica, 84: 313-320 (in Chinese).

Baskerville GL (1972) Use of logarithmic regression in the estimation of plant biomass. Canadian Journal of Forest Research 2: $49-53$

Bi H, Long Y, Turner J, Lei Y, Snowdon P, Li Y, Harper R, Zerihun A, Ximenes F (2010) Additive prediction of aboveground 
biomass for Pinus radiata (D. Don) plantations. Forest Ecol Manag 259: 2301-2314

Brandeis TJ, Delaney M, Parresol BR, Royer L (2006) Development of equations for predicting Puerto Rican subtropical dry forest biomass and volume. Forest Ecol Manag 233: 133-142

Canadell J, Riba M, Andrés P (1988) Biomass Equations for Quercus ilex L. in the Montseny Massif, Northeastern Spain. Forestry 61: 137-147

Carvalho JP, Parresol BR (2003) Additivity in tree biomass components of Pyrenean oak (Quercus pyrenaica Willd.). Forest Ecol Manag 179: 269-276

Case BS, Hall RJ (2008) Assessing prediction errors of generalized tree biomass and volume equations for the boreal forest region of west-central Canada. Canadian Journal of Forest Research 38: 878-889

Castedo-Dorado F, Gómez-García E, Diéguez-Aranda U, Barrio-Anta M, Crecente-Campo F (2012) Aboveground stand-level biomass estimation: a comparison of two methods for major forest species in northwest Spain. Ann Forest Sci 69: 735-746

Durkaya A, Durkaya B, Ünsal A (2009) Predicting the above-ground biomass of calabrian pine (Pinus brutia Ten.) stands in Turkey. African Journal of Biotechnology 8: 2483-2488

Gómez-García E, Crecente-Campo F, Diéguez-Aranda U (2013) Above-ground biomass equations for birch (Betula pubescens Ehrh.) and pedunculate oak (Quercus robur L.) in north western Spain. Madera y Bosques 19: 71-91(in Spanish)

Gómez-García E, Crecente-Campo F, Tobin B, Hawkins M, Nieuwenhuis M, Diéguez-Aranda U (2014) A dynamic volume and biomass growth model system for even-aged downy birch stands in south-western Europe. Forestry 87: 165-176

Gurdak DJ, Aragão LEOC, Rozas-Dávila A, Huasco WH, Cabrera KG, Doughty CE, Farfan-Rios W, Silva-Espejo JE, Metcalfe DB, Silman MR, Malhi Y (2014) Assessing above-ground woody debris dynamics along a gradient of elevation in Amazonian cloud forests in Peru: balancing above-ground inputs and respiration outputs. Plant Ecology \& Diversity 7: 143-160

Hasenauer H, Monserud RA, Gregoire TG (1998) Using simultaneous regression techniques with individual-tree growth models. Forest Sci 44: 87-95

Jacoby WG (2000) Loess: a nonparametric, graphical tool for depicting relationships between variables. Electoral Studies 19: 577-613

Jenkins JC, Chojnacky DC, Heath LS, Birdsey RA (2003) National-scale biomass estimators for United States tree species. Forest Sci 49: 12-35

Li H, Zhao P (2013) Improving the accuracy of tree-level aboveground biomass equations with height classification at a large regional scale. Forest Ecol Manag 289: 153-163

Luo W, Zhang W, Huang Y (2009) Cork oak. China Forestry Publishing House, Beijing (in Chinese).

Menéndez-Miguélez M, Canga E, Barrio-Anta M, Majada J, Álvarez-Álvarez P (2013) A three level system for estimating the biomass of Castanea sativa Mill. coppice stands in north-west Spain. Forest Ecol Manag 291: 417-426

Ter-Mikaelian MT, Korzukhin MD (1997) Biomass equations for sixty-five North American tree species. Forest Ecol Manag 97: $1-24$

Muukkonen P (2007) Generalized allometric volume and biomass equations for some tree species in Europe. European Journal of Forest Research 126: 157-166

Návar J, Méndez E, Dale V (2002) Estimating stand biomass in the Tamaulipan thornscrub of northeastern Mexico. Ann Forest Sci 59: 813-821

Návar J (2009) Allometric equations for tree species and carbon stocks for forests of northwestern Mexico. Forest Ecol Manag 257: 427-434

Parresol BR (1999) Assessing Tree and Stand Biomass:A Review with Examples and Critical Comparisons. Forest Sci 45: 573-593

Parresol BR (2001) Additivity of nonlinear biomass equations. Canadian Journal of Forest Research 31: 865-878

Paulo JA, Tomé M (2010) Predicting mature cork biomass with t years of growth from one measurement taken at any other age. Forest Ecol Manag 259: 1993-2005 
Peng H, Lu Y (2012) Model selection in linear mixed effect models. J Multivariate Anal 109: 109-129

Ritchie M, Zhang J, Hamilton T (2013) Aboveground Tree Biomass for Pinus ponderosa in Northeastern California. Forests 4: $179-196$

Ruiz-Peinado R, Del Rio M, Montero G (2011) New models for estimating the carbon sink capacity of Spanish softwood species. Forest Systems 20: 176-188

Saint-André L, M Bou AT, Mabiala A, Mouvondy W, Jourdan C, Roupsard O, Deleporte P, Hamel O, Nouvellon Y (2005) Age-related equations for above- and below-ground biomass of a Eucalyptus hybrid in Congo. Forest Ecol Manag 205: 199-214 Sajdak M, Velázquez-Martí B, López-Cortés I, Fernández-Sarría A, Estornell J (2014) Prediction models for estimating pruned biomass obtained from Platanus hispanica Münchh. used for material surveys in urban forests. Renew Energ 66: 178-184 Sakia RM (1992) The Box-Cox transformation technique: a review. The statistician 41: 169-178

Sánchez-González M, Ca Ellas I, Montero González G (2007) Generalized height-diameter and crown diameter prediction models for cork oak forests in Spain. Investigación agraria. Sistemas y recursos forestales 16: 76-88

Sánchez-González M, Tomé M, Montero G (2005) Modelling height and diameter growth of dominant cork oak trees in Spain. Ann Forest Sci 62: 633-643

Schmidt A, Poulain M, Klein D, Krause K, Peña-Rojas K, Schmidt H, Schulte A (2009) Allometric above-belowground biomass equations for Nothofagus pumilio (Poepp. \& Endl.) natural regeneration in the Chilean Patagonia. Ann Forest Sci 66: 513

Shaiek O, Loustau D, Trichet P, Meredieu C, Bachtobji B, Garchi S, Aouni MH (2011) Generalized biomass equations for the main aboveground biomass components of maritime pine across contrasting environments. Ann Forest Sci 68: $443-452$

Snorrason A, Einarsson SF (2006) Single-tree biomass and stem volume functions for eleven tree species used in Icelandic forestry. Icelandic Agricultural Sciences 19: 15-24

Su X, Yan X, Tsai C (2012) Linear regression. Wiley Interdisciplinary Reviews: Computational Statistics 4: 275-294

Fonseca TJF, Parresol BR (2001) A new model for cork weight estimation in Northern Portugal with methodology for construction of confidence intervals. Forest Ecol Manag 152: 131-139

Tian Q, Zhou R, Zhang J (1997) Biomass of Quercus variabilis population. Journal of Beijing Forestry University 19 (SuPP.2): 113-117 (in Chinese).

Torres Vélez DA, Del Valle JI (2007) Growth and yield modelling of Acacia mangium in Colombia. New Forest 34: 293-305

Vallet P, Dhôte J, Moguédec GL, Ravart M, Pignard G (2006) Development of total aboveground volume equations for seven important forest tree species in France. Forest Ecol Manag 229: 98-110

Wauters JB, Coudert S, Grallien E, Jonard M, Ponette Q (2008) Carbon stock in rubber tree plantations in Western Ghana and Mato Grosso (Brazil). Forest Ecol Manag 255: 2347-2361

Xu H (1998) Studies on standing tree biomass models and the corresponding parameter estimation. Dissertation, Beijing Forestry University (in Chinese).

Zeng WS, Zhang HR, Tang SZ (2011) Using the dummy variable model approach to construct compatible single-tree biomass equations at different scales-a case study for Masson pine (Pinus massoniana) in southern China. Canadian Journal of Forest Research 41: 1547-1554

Zianis D, Mencuccini M (2004) On simplifying allometric analyses of forest biomass. Forest Ecol Manag 187: $311-332$

Zianis D, Muukkonen P, Mäkipää R, Mencuccini, M (2005) Biomass and stem volume equations for tree species in Europe. Silva Fennica Monographs 4: 63

Zianis D, Xanthopoulos G, Kalabokidis K, Kazakis G, Ghosn D, Roussou O (2011) Allometric equations for aboveground biomass estimation by size class for Pinus brutia Ten. trees growing in North and South Aegean Islands, Greece. European Journal of Forest Research 130: 145-160 